\title{
Investigation of Abrasive Cutting of Ceramic Matrix Composites Based on Thin-Walled Elements Using Diamond Wire
}

\author{
Magdalena WIŚNIEWSKA*, Mateusz PUDŁOWSKI, Christian GAUGGEL, Dariusz POROŚ
}

\begin{abstract}
Ceramic Matrix Composites $(\mathrm{CMC})$ are innovative materials used in industries such as aviation, space and automotive because of their exceptional properties. However, an incorrect choice of the cutting method for such type of material may lead to delamination of a composite structure and reduce structure strength shortening its service life. The most commonly used forms of processing these materials are laser cutting technologies, water jet cutting or electro erosive machining. This prospective study was designed to investigate the possibilities and usefulness of applying the abrasive diamond wire for cutting CMC composites, specifically composite pipes made of $\mathrm{C} / \mathrm{C}$-SiC with the Liquid Silicone Infiltration (LSI). A complex microstructure of this material translates into significant machining difficulties. This paper presents the results of the preliminary tests and describes the impact of technological parameters on surface quality, edge damage and tool behaviour and wear. Briefly, a wire-reinforced permanently with a diamond grain of $120 / 140 \mu \mathrm{m}$ was selected. The cutting speed between 5 and $15 \mathrm{~m} / \mathrm{s}$ and the wire pressure for two values of $4,4 \mathrm{~N}$ and $5,5 \mathrm{~N}$ (they were selected experimentally) were used as variable parameters. Expectations for cutting effects focused on assessing edge quality (potential edge chipping), surface quality and answering the question of whether the method promotes material delamination. Preliminary results have shown that cutting with diamond wire is well suited for $\mathrm{CMC}$ materials and a surface quality of less than $2 \mu \mathrm{m}$ is fully satisfactory. It has been shown that the obtained values of surface roughness correspond to industrial conditions and are competitive or even better than for other machining technologies. Despite the initial satisfactory results, the research requires further development.
\end{abstract}

Keywords: abrasive diamond wire; CMC; CMC cutting methods; surface quality

\section{INTRODUCTION}

The majority of standard technical ceramics have high heat and abrasion resistance while having a low density. However, their low fracture resistance prevents their use in many applications [1]. The solution to this problem is the use of ceramic matrix composite (CMC). These materials were designed to work in conditions that usually combine high temperatures, load, and corrosive atmosphere. Due to extraordinary properties, invented in the 1960s CMC materials find many applications in modern industry. The growth of the global CMC market is dictated mainly by the increasing demand from the aviation and space sectors, where these composites are used as components of engines, heat shields or turbine blades. Also, CMC materials are used in the automotive (braking system elements), defence (personal shields and armoured vehicles, ballistics), biotechnology (implants) and nuclear power industries [2]. Due to the relatively recent enter of CMC materials for industrial applications, publications describing machining problems are still rare, this especially applies to the topic of diamond wire processing. Previous publications mainly describe the issues of drilling holes [3], milling [4] grinding [5] high-energy water jet treatment $[6,7]$ and the use of electrical discharge technologies [8]. The scope of research also includes the use of modern laser technologies [9] and assisting the cutting process with ultrasonic vibrations [10]. Based on these publications and one of the newer summaries of the achievements so far [11] in the field of processing CMC composites, the following conclusions can be drawn: $\mathrm{SiC}$ matrix and fibres cause severe tool wear during machining, carbide tools cannot be used due to catastrophic tool wear so most researchers use diamond abrasive tools. Many authors [13, 12] mention numerous disadvantages of conventional processing such as poor machined surface quality, serious machining defects, and serious tool wear. To meet surface quality requirements, the machining efficiency is often sacrificed, which is detrimental in reducing the machining costs. An interesting modification when it comes to dealing with the properties of CMC materials is laser-assisted machining [14]. These methods solve the poor machinability caused by high hardness and high brittleness, thereby extending the tool life, thus improving machining quality and efficiency. Researchers summarized that the machining defects of CMC composites were the combination of matrix cracking, fiber fractures, and interfacial debonding $[15,16]$. Most of them believe that it is dictated primarily by the cutting forces. Based on previous studies, it can be concluded that the methods tested and described still leave much to be desired in terms of edge quality or surface quality. Machining problems on the production line forced the authors to look for another unconventional method of processing the CMC composite. Fiber reinforced $\mathrm{SiC}$ ceramic matrix composites are fiber-rich materials and it is observed that carbon fibers have a large number of machining defects which has a great impact on surface quality, which should be focused on. The purpose of this research was to assess the applicability of the abrasive diamond wire cutting method for the mentioned materials.

\section{THE PROCESS OF CUTTING WITH PERMANENTLY REINFORCED DIAMOND ABRASIVE WIRE}

Over the past 20 years, diamond abrasive wire cutting (DWS) has become the leading method for cutting silicon substrates [17]. It should be noted here that the diamond wire cutting method, depending on the mechanism of wire reinforcement, is divided into wire cutting in abrasive slurry method and cutting with wire permanently reinforced with diamond grits. The latter solution has recently been gaining interest due to higher efficiency, hence shorter cutting time and the possibility of reducing non-organic abrasive slurry [18].

Wire permanently coated with diamond grain embedded in a nickel matrix is a tool that allows increasing productivity by two or even three times compared to cutting in an abrasive slurry. Therefore, this method can potentially be used for a wide range of materials. A review of the literature and information published by companies 
operating in the area of diamond wire cutting found a few examples of applications of that tool other than those related to the production of silicon base wafers $[19,20]$ As abrasive diamond wire works-diamond particles permanently set on the tool surface are dragged along with the wire move as it was shown in Fig. 1. Interaction between wire motion and force that is pushing material into the moving wire $F_{d}$ in combination with the force of dragging diamond grits against wire motion (Fig. 2) produce a characteristic lined pattern on the cut surface (Fig. 1) [20]. The force exerted by the material pressed against the wire at the same time determines with which feed it is cut.
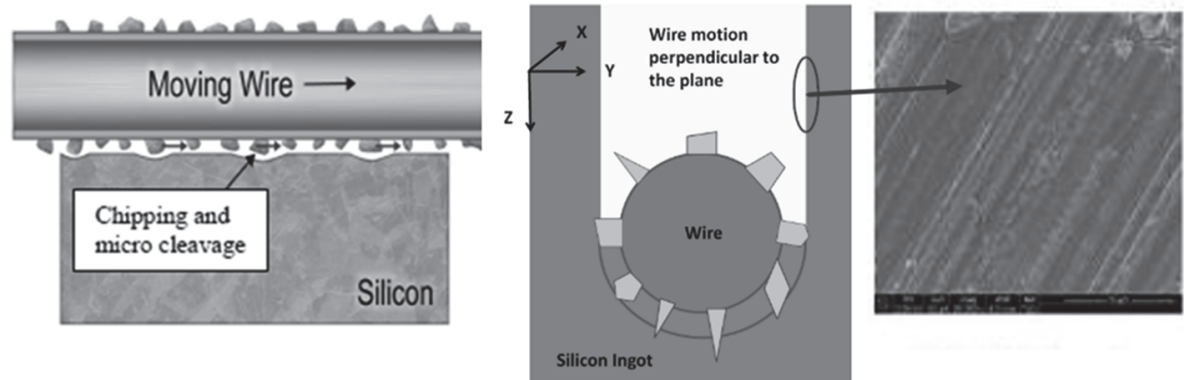

Figure 1 Illustration of the cutting mechanism by diamond wire showing "U-groove" formation and typical surface texture (microscopic photo of silicon crystal surface) [21, 22]

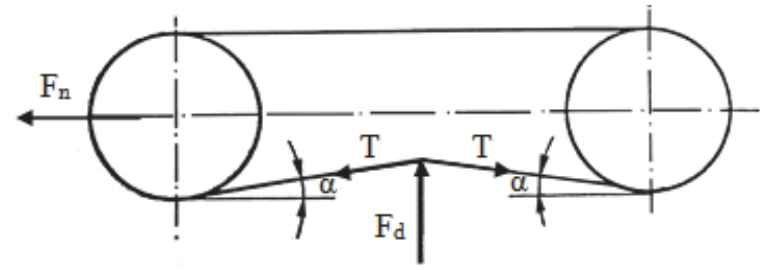

Figure 2 Schematic representation of the distribution of forces during wire cutting $\left(F_{n}\right.$ - wire tension, $F_{d}$ - the force of pressing the material to the wire, $\alpha$ wire bow angle, $T$ - wire stress) [5]

\section{CUTTING METHOD AND EXPERIMENT CONDITIONS}

Production of various composites with a wide range of properties and different machinability leads to the decision that the appropriate cutting technique should be selected individually. The selection criteria depend on the cutting efficiency, surface quality, material thickness and its physical properties etc. The use of an incorrect cutting technique may lead to delamination of the composite structure around the cut edge. Cutting composite materials using machining methods is associated with providing the right parameters and the tool to minimize or eliminate delamination [23]. Also, the need to ensure the safe removal of harmful dust generated during machining is necessary.

A pipe made with the Liquide Silicon Infiltration (LSI) method using a CMC material $(\mathrm{C} / \mathrm{C}-\mathrm{SiC})$ with a length of $160 \mathrm{~mm}$, external diameter ø128 $\mathrm{mm}$ and wall thickness 4 mm was used for the test (Fig. 3). The pipe was cut using a wire saw machine designed for straight-line cutting. The cutting was carried out using a PS-4 wire saw (Fig. 4a) with wires permanently reinforced with a diamond grain (HK Präzisionstechnik, Germany). A wire with a diameter of $1000 \mu \mathrm{m}$ and the diamond grain about $\sim 120 / 140 \mu \mathrm{m}$ was used (Fig. 3d). Wire tension $\left(F_{n}\right)$ was constant at $145 \mathrm{~N}$. The $F_{n}$ value is characteristic for a given type of wire and selected so that the tool does not break. It should also be taken as a constant value because it does not affect the cutting process [24]. The selection of described tools followed the previous experience. Due to its specific structure and properties, the CMC material can be referred to as hard to machine material, therefore thinner wire with smaller grains could have been damaged prematurely. a)

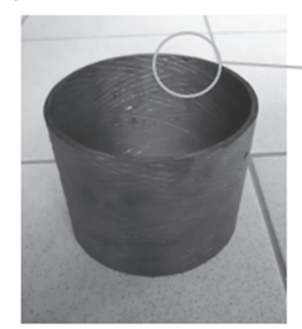

c)

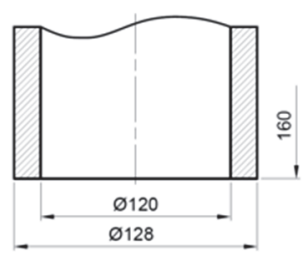

b)

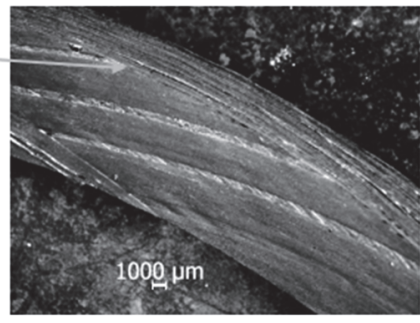

d)

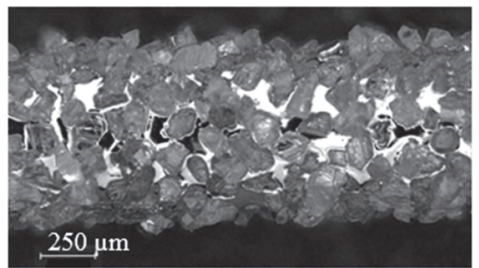

Figure 3 a) The CMC pipe used for experiments; b) edge and macro photo of $\mathrm{CMC}$ pipe; $c$ ) the CMC pipe dimensions, d) HK Präzisionstechnik diamond abrasive wire

a) b)

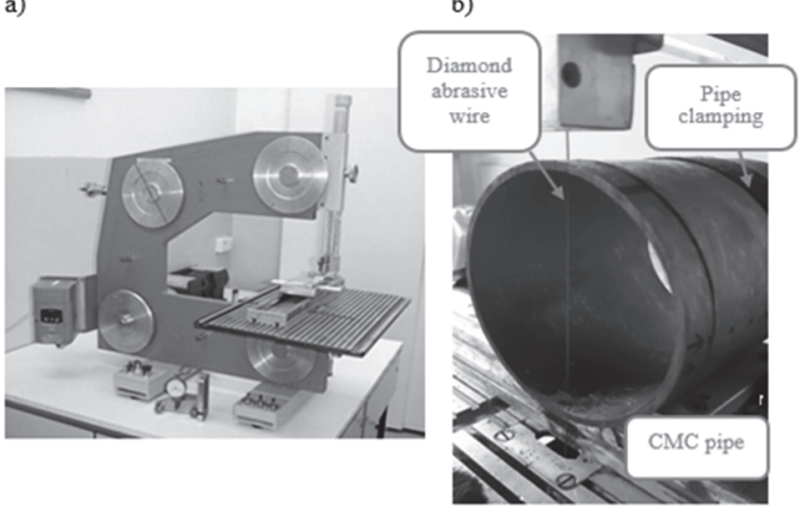

Figure 4 a) The PS-4 wire saw; b) cutting machine working area

The process parameters were selected based on the tests for different values of cutting speed $v_{c}$ and force $F_{d}$ used when the pipe was pushed against a moving wire (Tab. 1). The $F_{d}$ value is calculated based on the load that is set and needed for the material table to move smoothly 
relative to the working wire. The $F_{d}$ value below $4,4 \mathrm{~N}$ was too low for the cutting process, and the value of $v_{c}=5 \mathrm{~m} / \mathrm{s}$ did not give satisfactory results in terms of cutting time. The process was carried out without the use of coolant.

Table 1 Parameters used during the cutting process and obtained $R$ a results

Table 1 Parameters used during the cutting process and obtained Ra results
\begin{tabular}{|c|c|c|c|c|}
\hline & $v_{c} / \mathrm{m} / \mathrm{s}$ & $F_{d} / \mathrm{N}$ & $t / \mathrm{s}$ & $R a / \mu \mathrm{m}$ \\
\hline 1 & 5 & 4,4 & 646 & 2,65 \\
\hline 2 & 5 & 5,5 & 477 & 4,05 \\
\hline 3 & 10 & 4,4 & 517 & 2,51 \\
\hline 4 & 10 & 5,5 & 375 & 2,03 \\
\hline 5 & 15 & 4,4 & 480 & 2,73 \\
\hline 6 & 15 & 5,5 & 321 & 1,81 \\
\hline
\end{tabular}

The surface roughness of the cut-off elements and 3D surface profiles was measured and made using a surface roughness meter (Mitutoyo S-3000, Japan). For the purposes of the publication, only the $R a$ parameter was included due to its high popularity and very preliminary form of research. Microscopic images were made using a stereoscopic microscope (Zeiss Evo Ma25, Germany).

\section{EXPERIMENT RESULTS}

All experiments were performed in triplicates and all data were presented as mean \pm standard deviation. The differences were analysed using one-way analysis of variance (ANOVA) followed by the Tukey test. Data were analysed using IBM SPSS Statistics 26. Differences were considered significant at $p<0,05$.

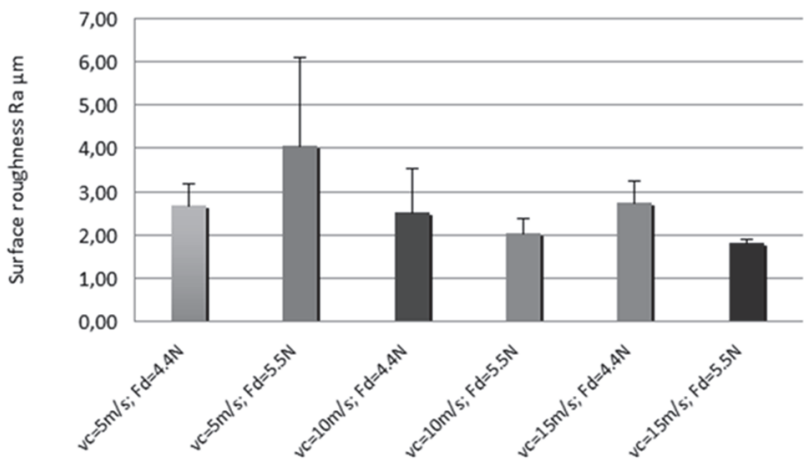

Figure 5 The results for surface roughness for different cutting parameters ( $n=$ $3), v_{c}$ - cutting speed, $F_{d}$ - feed speed

Obtaining results for surface quality measurement was difficult due to surface discontinuities in the structure of the pipes (Fig. 8). The heterogeneity of the structure is typical for composite materials. Determining sampling length and place so that the stylus does not fall into discontinuous layers forming the pipe structure was problematic. In test trials only $R a$ parameter was taken into account and waviness was not, due to the small wall thickness, which generated great measurement issues. Presented pipes are elements used in industry and this research was intended to test indicated cutting technology and the only controlled parameter was roughness. Fig. 5 shows that the results for wire pressure $F_{d}=4,4 \mathrm{~N}$, were comparable and, similar surface roughness results were obtained for all the cutting speeds used. When a wire pressure $F_{d}=5,5 \mathrm{~N}$ was used, the surface roughness improved as the cutting speed increased. However, there is no significant difference between surface roughness $(p>$ $0,05)$. The obtained surface roughness results are more than twice lower than those obtained by cutting ceramic composites with a high-energy water jet [7], and are comparable with the results obtained with the power erosion machining [10].

The following 3D profiles show selected examples of sections where roughness measurements were taken (Fig. 6 and Fig. 7). These representative samples were shown due to the best quality achieved. In the $x$-direction, the data is collected with $N x$ number of data points while in the $y$ direction there are $\mathrm{Ny}$ lines (profiles) and beneath the 3D images, the profile extraction can be seen. Looking at the $3 \mathrm{D}$ profiles, it is easy to notice the characteristic texture of the surface [23], typical for cutting with wire permanently coated with diamond grits, which was mentioned earlier. Together with the microscopic photos, the $3 \mathrm{D}$ profiles give full information about the real condition and topography of the surface after wire cutting.
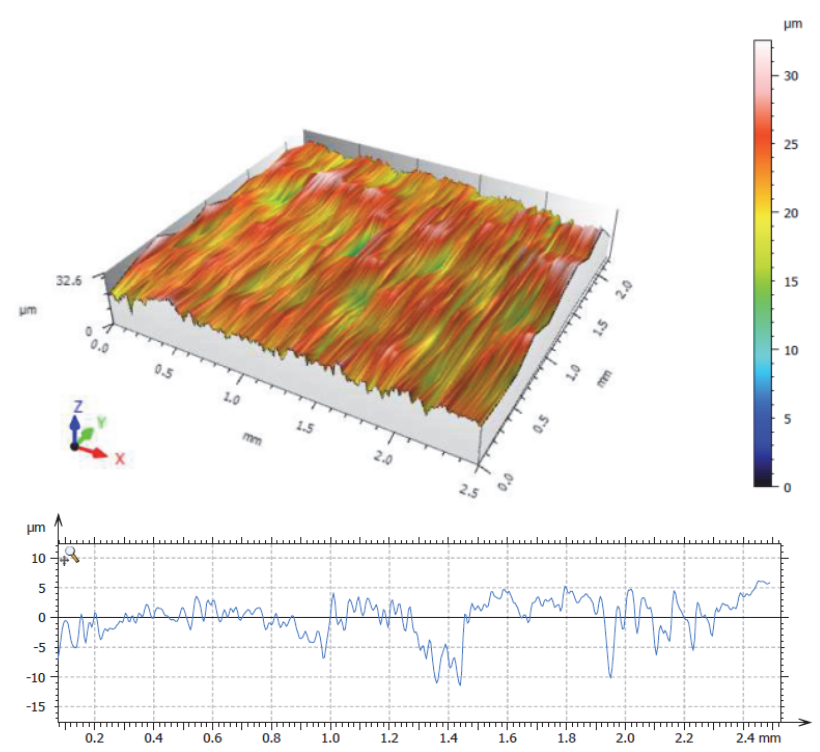

Figure $63 \mathrm{D}$ profile for sample number 4
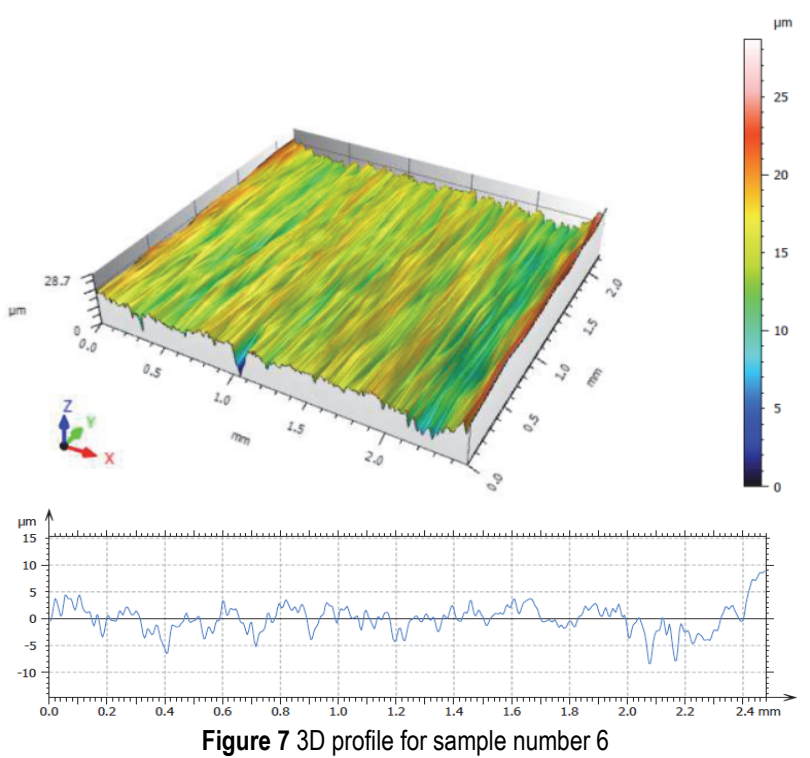

This study has been able to demonstrate that DWS can be identified as a suitable method for cutting CMC materials. Preliminary tests show that more work can be done on the efficiency and quality of the surface after cutting. The tool showed no signs of damage or wear such 
as chipping, cracks or abrasion of grains. However, the process itself requires the active removal of dirt and the use of personal protective equipment as it produces a high amount of dust. Fig. 8 shows no damage, burrs or delamination at the edge after cutting with DWS. Besides surface machining defects, subsurface machining defects are also an important component of machined surface quality. Surface machining defects are easy to observe, using an optical microscope or scanning electron microscope (SEM). But subsurface defects are not easy to observe. However, the material was heating up while cutting. Microscope photography of surfaces after wire cutting does not show interlaminar cracks (Fig. 8), only manufacturing process imperfections are visible. Diamond abrasive wire cutting can be considered as a safe cutting method with minimal damage to the cutting material.
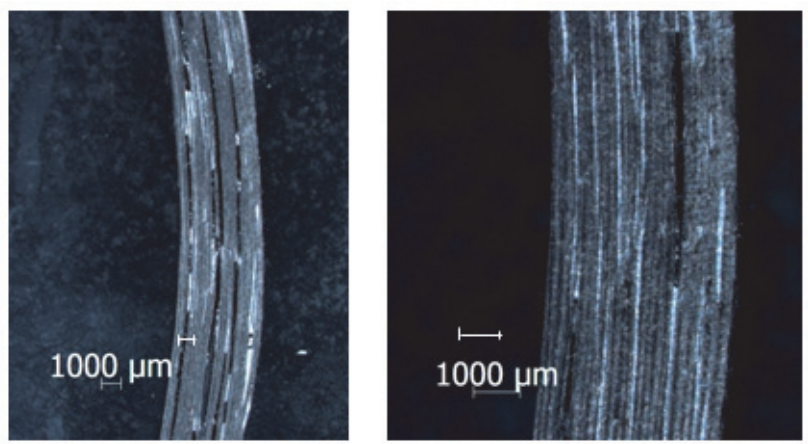

Figure 8 Microscopic images of CMC pipe surface and edges after cutting with DWS

\section{CONCLUSION}

Understanding the cutting mechanisms is important for maximizing cutting speed and process efficiency while minimizing the damages to the cutting material. This study showed that diamond abrasive wire is a great tool for cutting CMC materials and showed no problems typical for other cutting methods. The presented technology is not a typical method used for such material so it can be said that it is an innovative approach. Nevertheless, the presented technology can be successfully used in the automotive industry (for pre-cutting of brake discs), aviation (shaping thermal covers for rockets or aircraft) or energy (cutting pipes used to transport hot liquids). Based on experience with other hard-machinable materials, the authors decided to try to apply wire cutting. This method has proven itself many times before for materials for which the use of conventional methods has failed. This is not a common approach as the wire cutting method is the industry standard for cutting silicon substrate wafers. However, based on the fact that diamond tools are very versatile and resistant to abrasive wear, and the wires with their small diameters and cutting forces do not cause cracking even such brittle materials as silicon monocrystals, it was decided to choose precisely this tool. The presented surface roughness values obtained during the tests correspond to the standards set in the industry and are more than two times lower than those obtained with, for example, water jet cutting $[13,7]$. However, the selected method identified several local stresses exerting on the material and its surfaces, such as grit size variation, variability in the cutting forces, wire core diameter and distribution of grits over the wire; increasing grit size results in deeper damage to the material and increase in surface roughness.The limitation for the use of this method in industrial conditions may be the difficulty in assessing the wear of the tool, which involves the possibility of a sudden break of the wire. However, where the material is very difficult to process and conventional methods fail, with relatively little financial and time required determining the appropriate cutting conditions, this method seems to be a good choice. The tests described in the work can therefore be a hint of what methods can be used for CMC materials and what to look for when choosing parameters. Nevertheless, preliminary tests for cutting CMC materials are promising. Further research should be divided into several stages, which would focus on the optimization of the cutting process efficiency (changes and the impact of cutting parameters, the use of different types of abrasive wires) and the impact of this technique on the quality of the workpiece (quality of the surface layer after the diamond wire cutting process).

\section{REFERENCES}

[1] Oczoś, K. E. (2011). Problemy kształtowania ubytkowego kompozytów włóknistych $\mathrm{z}$ osnową polimerową i ceramiczną. Cz. II. Mechanik, 79-86

[2] Ohji, T. \& Singh, M. (2016). Engineered ceramics: current status and future prospects. Hoboken: John Wiley \& Sons, Inc. https://doi.org/10.1002/9781119100430

[3] Xing, Y. (2017). Assessment in drilling of C/C-SiC composites using brazed diamond drills. Journal of Manufacturing Processes, 26, 31-43. https://doi.org/10.1016/j.jmapro.2017.01.006

[4] Meng, H. (2019). Experimental study on milling performance of $2 \mathrm{D} \mathrm{C} / \mathrm{SiC}$ composites using polycrystalline diamond tools. Ceramics International, 45, 10581-10588. https://doi.org/10.1016/j.ceramint.2019.02.124

[5] Tashiro, T., Fujiwara, J., \& Takenaka, Y. (2007). Grinding of C/C-SiC Composite in Dry Method. Springer, conference paper, 351- 352. https://doi.org/10.1007/1-84628-559-3_72

[6] Hamatani, G. \& Ramulu M. (1990). Machinability of High Temperature Composites by Abrasive Waterjet. Journal of Engineering Materials and Technology, 112, 381-386. https://doi.org/10.1115/1.2903346

[7] Ramulu, M., Jenkins, M. G., \& Guo, Z. (2001). Abrasive Water Jet Machining Mechanisms in Continuous-Fiber Ceramic Composites. Journal of Composites Technology and Research, 23, 82-91. https://doi.org/10.1520/CTR10916J

[8] Hocheng, H., Guu, Y. H., \& Tai, N. H. (1998). The Feasibility Analysis of Electrical-Discharge Machining of Carbon-Carbon Composites. Material and manufacturing process, 13, 117-132. https://doi.org/10.1080/10426919808935223

[9] Dong, X. \& Shin, Y. C. (2017). Improved machinability of $\mathrm{SiC} / \mathrm{SiC}$ ceramic matrix composite via laser-assisted micromachining. The International Journal of Advanced Manufacturing Technology, 90, 731-739. https://doi.org/10.1007/s00170-016-9415-5

[10] Davim, J. P. (2010). Machining composite materials. Hoboken: John Wiley \& Sons, Inc.

[11] Qinglong, A., Jie, C., Weiwei M., \& Ming, C. (2021). Machining of $\mathrm{SiC}$ ceramic matrix composites: A review. Chinese Journal of Aeronautics 4, 540-567. https://doi.org/10.1016/j.cja.2020.08.001

[12] Azarhoushang, B. (2014). Wear of non-segmented and segmented diamond wheels in high-speed deep grinding of carbon fibre-reinforced ceramics. The International Journal 
of Advanced Manufacturing Technology, 74(9-12), 12931302. https://doi.org/10.1007/s00170-014-6082-2

[13] Gavalda, D. O. (2019). On understanding the microstructure of $\mathrm{SiC} / \mathrm{SiC}$ Ceramic Matrix Composites (CMCs) after a material removal process, Science and Engineering: A, 743, 1-11. https://doi.org/10.1016/.msea.2018.11.037

[14] Erdenechimeg, K., H.I. Jeong, C.M. Lee (2019). A study on the laser-assisted machining of carbon fiber reinforced silicon carbide, Materials, $12 \quad$ (13) https://doi.org/206110.3390/ma12132061

[15] Zhang, L., Sheng, W., Zhan, L., Weilin, Q., Ying, W., \& Tao, W. (2019). Influence factors on grinding force in surface grinding of unidirectional $\mathrm{C} / \mathrm{SiC}$ composites. Applied Composite Materials, 26(3), 1073-1085. https://doi.org/10.1007/s10443-019-09767-5

[16] Qu, S., Gong, Y., Yang, Y., Ming, C., Yao, S. (2018). Surface topography and roughness of silicon carbide ceramic matrix composites. Ceramics International, 44(12). 14742 14753. https://doi.org/10.1016/j.ceramint.2018.05.104

[17] Chunhui, C. \& Tsay, G. D. (2014). Distribution of diamond grains in fixed abrasive wire sawing process. The International Journal of Advanced Manufacturing Technology, 73(9-12), 1485-1494. https://doi.org/10.1007/s00170-014-5782-y

[18] Arkadeep, K. (2018). Diamond Wire Sawing of Solar Silicon Wafers: A Sustainable Manufacturing Alternative to Loose Abrasive Slurry Sawing. 15th Global Conference on Sustainable Manufacturing, Elsevier. https://doi.org/10.1016/j.promfg.2018.02.156

[19] Wiśniewska, M. \& Duda M. (2019). Possibilities and nonstandard applications of abrasive wires coated with diamonds. Mechanik, 10. https://doi.org/10.17814/mechanik.2019.10.81

[20] Wiśniewska, M. (2015). Cięcie materiałów trudnoobrabialnych strunami o różnej konstrukcji i metodyka oceny ich właściwości użytkowych, rozprawa doktorska. Wroctaw University of Science and Technology, Wroctaw.

[21] Bhushan, S. (2013). Characterizing Damage on Si Wafer Surfaces Cut by Slurry and Diamond Wire Sawing. Conference Record of the IEEE Photovoltaic Specialists Conference. https://doi.org/ 10.1109/PVSC.2013.6744298

[22] Bhushan, S. (2016). Surface characteristics and damage distributions of diamond wire sawn wafers for silicon solar cells, AIMS Materials Science, 3(2), 669-685. https://doi.org/10.3934/matersci.2016.2.669

[23] Neubrand, A. (2015). Investigation of cutting-induced damage in CMC bend bars, MATEC Web of Conferences, 29, 00004. https://doi.org/10.1051/matecconf/20152900004

[24] Ciałkowska, B. (2008). Cutting hard machinable materials with an abrasive wire. Scientific Papers of the Wroctaw University of Technology

\section{Contact information:}

\section{Magdalena WIŚNIEWSKA, drinż.}

(Corresponding author)

Departament of Mechanical Engineering,

Wroclaw University of Science and Technology,

Ignacego Łukasiewicza 5, 50-371 Wrocław, Poland

E-mail:m.wisniewska@pwr.edu.pl

Mateusz PUDŁOWSKI, mgr inż.

Gühring Sp. z 0.0.,

Al. Zagłębia Dabrowskiego 21, 41-300 Dabrowa Górnicza, Poland

E-mail: mpudlowski@guehring.pl

Christian GAUGGEL, M. Eng

Gühring KG,

Winterlinger Straße 12, 72488 Sigmaringen-Laiz, Germany

E-mail: christian.gauggel@guehring.de

Dariusz POROŚ, dr inż.

Departament of Mechanical Engineering,

Wroclaw University of Science and Technology,

Ignacego Łukasiewicza 5, 50-371 Wroclaw, Poland

E-mail:d.poros@pwr.edu.pl 